\title{
Lymphangiomyomatosis discovered by massive hemoptysis during general anesthesia -A case report-
}

\author{
Deokkyu Kim, Sung Nyu Lee, Sang-Kyi Lee, and Jeongwoo Lee \\ Department of Anesthesiology and Pain Medicine, Chonbuk National University Medical School, Jeonju, Korea
}

Lymphangiomyomatosis (LAM) is a rare lung disease that is characterized by the progressive proliferation of atypical smooth muscle-like cells, which leads to severe respiratory impairment and death. Dyspnea, cough, recurrent pneumothorax, and hemoptysis are the most common clinical symptoms of LAM. We report a 29-year-old female patient with massive hemoptysis during laparoscopic gynecologic surgery under general anesthesia, who was diagnosed with pulmonary LAM. (Korean J Anesthesiol 2012; 62: 371-374)

Key Words: Hemoptysis, Lymphangiomyomatosis.

Lymphangiomyomatosis (LAM) is a rare lung disease that is characterized pathologically by cysts and multifocal nodular proliferation of immature smooth muscle and perivascular epitheloid cells (LAM cells) [1]. LAM usually presents with the symptoms of progressive dyspnea, cough, recurrent pneumothorax, chylothorax, and hemoptysis. Most cases of LAM occur in women of reproductive age [1-3].

Detecting the disease at a pre-operative evaluation is very difficult because it does not show any specific symptoms at the early stages, and the chest x-ray findings are normal. We report an ectopic pregnant patient, who was normal at a pre-operative chest $\mathrm{x}$-ray, with massive hemoptysis during laparoscopic gynecologic surgery under general anesthesia. The patient was diagnosed with LAM by high resonance computed tomography (HRCT) and biopsy after surgery.

\section{Case Report}

A 29 -year-old, $54 \mathrm{~kg}$ female patient with a right fallopian pregnancy was admitted for emergent pelviscopic salpingectomy. Her past history and familial history were not specific. The preoperative ECG, chest x-ray (Fig. 1), and laboratory study were within normal range.

When she arrived in the operating room, the ECG, noninvasive blood pressure device, and pulse oximeter were applied. Her blood pressure (BP), heart rate (HR) and oxygen saturation $\left(\mathrm{SpO}_{2}\right)$ was $110 / 70 \mathrm{mmHg}, 87 \mathrm{bpm}$ and $99 \%$, respectively. Thiopental sodium $250 \mathrm{mg}$ and rocuronium 50 mg were injected. After 3 minutes of manual ventilation with $\mathrm{O}_{2} 2 \mathrm{~L} / \mathrm{min}, \mathrm{N}_{2} \mathrm{O} 4 \mathrm{~L} / \mathrm{min}$ and sevoflurane 4 vol\%, she was intubated with an internal diameter $7.0 \mathrm{~mm}$ endotracheal tube

Received: February 16, 2011. Revised: 1st, March 24, 2011; 2nd, May 12, 2011. Accepted: May 19, 2011.

Corresponding author: Jeongwoo Lee, M.D., Department of Anesthesiology and Pain Medicine, Chonbuk National University Medical School, 634-18, Geumam-dong, Deokjin-gu, Jeonju 561-712, Korea. Tel: 82-63-250-1979, Fax: 82-63-250-1240, E-mail: jw88lee@gmail.com () This is an open-access article distributed under the terms of the Creative Commons Attribution Non-Commercial License (http:// creativecommons.org/licenses/by-nc/3.0/), which permits unrestricted non-commercial use, distribution, and reproduction in any medium, provided the original work is properly cited. 


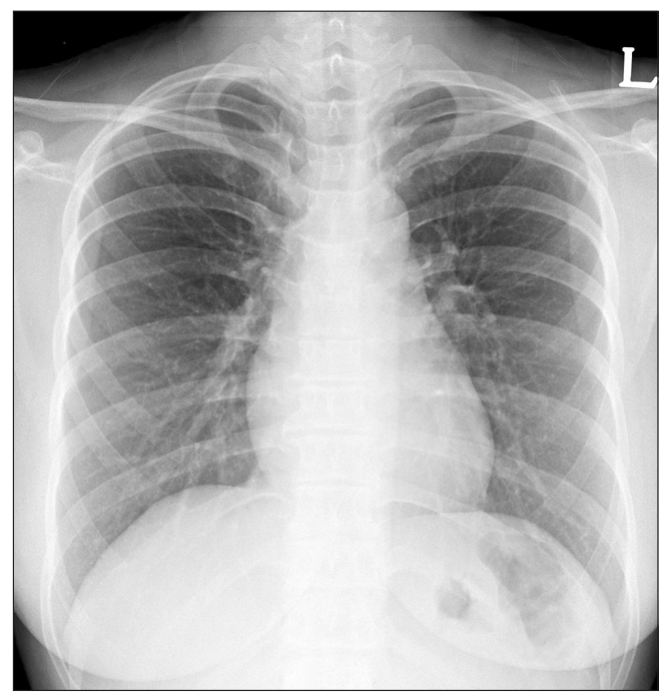

Fig. 1. The preoperative chest $x$-ray shows normal finding.

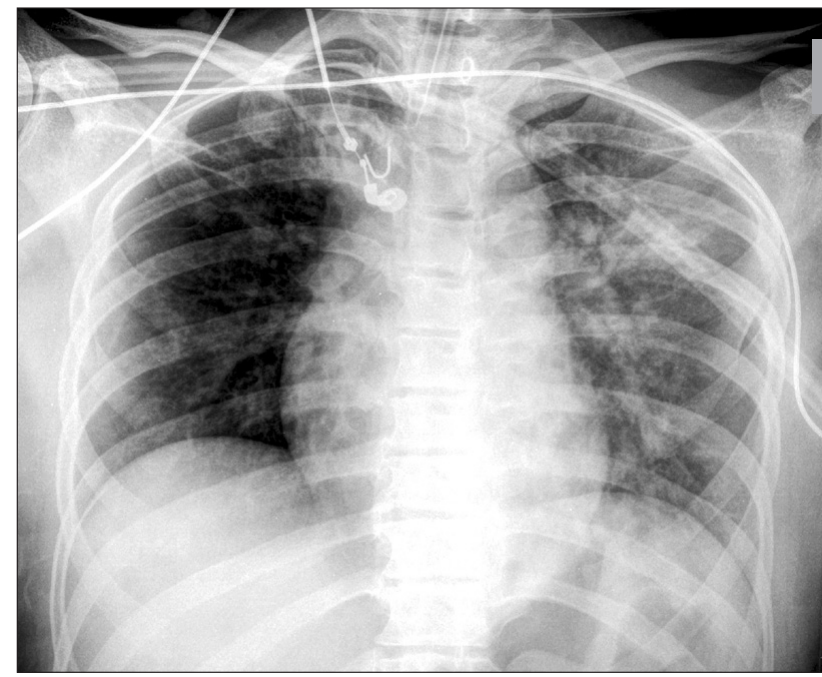

Fig. 2. The postoperative chest x-ray shows increased infiltration and consolidation with air-bronchogram.

under direct laryngoscopy. No problems were encountered during tracheal intubation and the breathing sound was clear at both lung fields. Mechanical ventilation was conducted as a tidal volume of $500 \mathrm{ml}$ and respiratory rate of 10 breaths/ min, and anesthesia was maintained with $\mathrm{O}_{2} 2 \mathrm{~L} / \mathrm{min}, \mathrm{N}_{2} \mathrm{O} 2 \mathrm{~L} /$ $\mathrm{min}$ and sevoflurane $2.5 \mathrm{vol} \%$. Her vital signs at this time were a $\mathrm{BP}$ of 140/90 mmHg, $\mathrm{HR}$ of $105 \mathrm{bpm}, \mathrm{SpO}_{2}$ of $99 \%$, end-tidal carbon dioxide partial pressure $\left(\mathrm{P}_{\mathrm{ET}} \mathrm{CO}_{2}\right)$ of $28 \mathrm{mmHg}$, and peak inspiratory pressure of $14 \mathrm{cmH}_{2} \mathrm{O}$. The position of the patient was changed to the Trendelenburg position at 10 minutes after the skin incision. Her vital signs were stable during the operation, and the peak inspiratory pressure was $20-22 \mathrm{cmH}_{2} \mathrm{O}$ during pneumoperitoneum. Inhalation anesthetics were

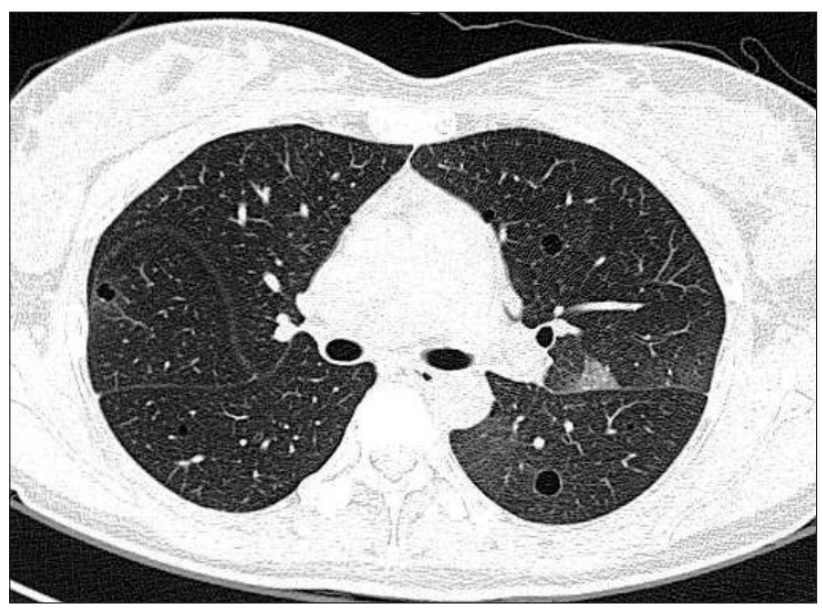

Fig. 3. The CT scan shows numerous well defined, thin-walled round or oval shaped cysts throughout the lungs.

stopped and the lungs were ventilated with $100 \% \mathrm{O}_{2}$ during skin closure. The patient received pyridostigmine $10 \mathrm{mg}$ and glycopyrrolate $0.4 \mathrm{mg}$ to reverse the neuromuscular block.

When she breathed spontaneously, a large amount of fresh blood was found in endotracheal tube with cough. At this point, her BP, $\mathrm{HR}$, and $\mathrm{SpO}_{2}$ were $150 / 105 \mathrm{mmHg}, 125 \mathrm{bpm}$, and $100 \%$, respectively. Hemoptysis occurred several times but the amount of bleeding decreased gradually. The total amount of blood loss was approximately $300 \mathrm{ml}$. Her mental status became alert and $93 \% \mathrm{SpO}_{2}$ by spontaneous respiration with endotracheal tube was sustained with room air. An airway injury was evaluated due to endotracheal intubation by using fiberoptic bronchoscope but there were no specific finding in the trachea and main bronchus. No intraoral bleeding was observed.

Her vital signs were gradually stable but she was transferred to ICU with endotracheal tube for the evaluation and the further management of hemoptysis. At ICU, BP was $110-120 / 70-80$ mmHg, HR was $80-90 \mathrm{bpm}$, and $\mathrm{ABGA}$ with a $\mathrm{FiO}_{2} 0.4$ was $\mathrm{pH}$ 7.42, $\mathrm{PaO}_{2} 117 \mathrm{mmHg}, \mathrm{PaCO}_{2} 32 \mathrm{mmHg}, \mathrm{HCO}_{3} 21.9 \mathrm{mmol} / \mathrm{L}$, BE $-2.2 \mathrm{mmol} / \mathrm{L}$, and $\mathrm{SaO}_{2} 99 \%$ at with spontaneous ventilation. Postoperative chest $\mathrm{x}$-ray showed that infiltration on both lung fields, especially left lung, was increased, and consolidation with air bronchogram was found (Fig. 2). No more hemoptysis was complained except for a small amount of blood in the endotracheal tube during suction, so the patient was extubated 10 hours after surgery. After extubation, she was stable, and did not complain of dyspnea without an oxygen supply. HRCT to evaluate the cause of hemoptysis revealed multiple cystic changes in the total lung field (Fig. 3). From the findings of HRCT, the characteristic symptoms and ectopic pregnancy of the patient, she was diagnosed with LAM, which was confirmed by a lung biopsy. 


\section{Discussion}

LAM is known as a rare lung disease, which occurs mostly in reproductive aged women, but has been reported in men [4]. LAM occurs in sporadically or in association with tuberous sclerosis, and can develop anywhere that lymphatic tissues exist, such as perivascular, perilymphangeal, alveolar wall, or peri-bronchial area [5]. Cornog and Enterline [6] first referred to this disease as LAM in 1966 to distinguish it from tuberous sclerosis because the pathological findings of mediastinal lymphangiomyoma along with chylothorax are similar to the proliferation of smooth muscle cells of tuberous sclerosis. According to the European Respiratory Society guideline in 2010 [1], sporadic LAM occurs $\sim 1$ in 400,000 adult women; in tuberous sclerosis complex, LAM occurs in $30-40 \%$ of adult women.

Once the pulmonary symptoms manifest, it is mostly aggravated to pulmonary failure or cor pulmonale, and leads to death in 10 years. The most common pulmonary symptoms are dyspnea, cough, hemoptysis, and pneumothorax with an abrupt onset, etc. Pleural effusion and intraabdominal hemorrhage can be accompanied. The symptoms characteristically can be aggravated by pregnancy. Once the bronchioles are obstructed by proliferating smooth muscle cells, the clinical features of obstructive lung disease are shown but a pneumothorax can also occur because air retention increases the size of the alveoli and produces bullae or cysts. The invasion of blood vessels and lymphatics are the cause of hemoptysis and chylothorax, respectively [7].

Generally, LAM is suspected by the characteristic clinical features in reproductive aged women, obstructive patterns of the pulmonary function, increased lung volume, defect gas exchange, and reticulonodular interstitial infiltrates on the chest x-ray. The pathological findings by a lung biopsy has been used for confirmation in the past, but the cystic changes in HRCT and accompanying characteristic clinical features allow a diagnosis without a biopsy [2]. There is no definite treatment that effectively reverses the functional abnormalities or stops the progressing lung injury in LAM. Because LAM is mostly a disease of reproductive aged women and can worsen during pregnancy $[1,8,9]$, female hormonal therapy has been utilized. The hormonal therapy includes oophorectomy [10], tamoxifen [11] and gonadotropin-release hormone analogues [12] as a method of anti-estrogen. On the other hand, progesterone treatment [1] is preferably recommended at present. The symptomatic treatment for the condition includes standard therapies for obstructive pulmonary disease and operation for a recurrent pneumothorax [4]. In addition, LAM is one of the indications of lung transplantation, and it has a high success rate [13].
LAM patients commonly complain of dyspnea as the first clinical symptom. On the other hand, in this case, she did not complain of dyspnea or cough before the operation and had abrupt massive hemoptysis as the first symptom. The common causes of hemoptysis during anesthesia are airway injury by endotracheal intubation, pneumonia, bronchitis, tuberculosis, or tumors, etc. Tracheal injury could be ruled out by a fiberoptic bronchoscopy examination in this case. Pneumonia and bronchitis also could be ruled out as a cause of the hemoptysis because the hemoptysis in pneumonia and bronchitis is characterized as blood-tinged sputum rather than massive bleeding. Normally, tuberculosis and tumors can be diagnosed preoperatively by chest x-ray.

In this patient, LAM was not suspected before surgery because she had no medical history and no specific findings on the chest x-ray. It is unclear why her disease progressed abruptly. In our opinion, there were several aggravating factors. First, she became ectopic pregnant recently, which may have aggravated the LAM $[4,8,9]$. Second, the most important cause of hemoptysis is mechanical ventilation during general anesthesia for surgery due to an ectopic pregnancy $[4,5,14]$. Moreover, the use of $\mathrm{N}_{2} \mathrm{O}$ can be the cause of hemoptysis because she had cystic changes in her lung $[3,4]$. Finally, the specific requirement for the pelviscopic surgery, such as Trendelenburg position and pneumoperitoneum increased the airway pressure [15], which may have aggravated the lung injury and led to hemoptysis.

Most LAM patients meet anesthesiologists for the surgical treatment of a recurrent pneumothorax or pregnant women to have painless labor or a cesarean section. Anesthetic management for LAM patients is related mainly to pulmonary complications. The complications include pneumothorax or intrapulmonary bleeding due to the severe obstruction of the bronchioles as well as cystic changes in the pulmonary parenchyma during mechanical ventilation. Because of pulmonary complications due to mechanical ventilation, regional anesthesia is preferred over general anesthesia. It is expected that epidural anesthesia is safer than spinal anesthesia because hydration for hemodynamic stability during spinal anesthesia can cause pulmonary edema [14]. Furthermore, epidural anesthesia allowed careful titration and avoidance of a high motor block, which would have been catastrophic to someone with such limited respiratory reserve [5]. When general anesthesia is requested, nitrous oxide should be avoided in patients with cystic lung disease or a closed pneumothorax, and a mechanical ventilator strategy to decrease airway pressure is needed [4].

In conclusion, this paper reported the occurrence of hemoptysis due to mechanical ventilation during general anesthesia in a LAM patient with pulmonary cystic changes, who did not 
show any signs of LAM before operation. The possibility of LAM should be considered if a reproductive aged woman has unexplained massive hemoptysis or pneumothorax during general anesthesia. Anesthesiologists should carefully manage the pulmonary complications during anesthesia in LAM patients.

\section{References}

1. Johnson SR, Cordier JF, Lazor R, Cottin V, Costabel U, Harari S, et al. European Respiratory Society guidelines for the diagnosis and management of lymphangioleiomyomatosis. Eur Respir J 2010; 35 : 14-26.

2. Taveira-DaSilva AM, Steagall WK, Moss J. Lymphangioleiomyomatosis. Cancer Control 2006; 13: 276-85.

3. Johnson SR, Tattersfield AE. Clinical experience of lymphangioleiomyomatosis in the UK. Thorax 2000; 55: 1052-7.

4. McLoughlin L, Thomas G, Hasan K. Pregnancy and lymphangioleiomyomatosis: anaesthetic management. Int J Obstet Anesth 2003; 12: $40-4$.

5. Oxorn DC, Landrigan P. Anaesthetic management for oophorectomy in pulmonary lymphangiomyomatosis. Can J Anaesth 1987; 34: $512-4$

6. Cornog JL Jr, Enterline HT. Lymphangiomyoma, a benign lesion of chyliferous lymphatics synonymous with lymphangiopericytoma. Cancer 1966; 19: 1909-30.

7. Taylor JR, Ryu J, Colby TV, Raffin TA. Lymphangioleiomyomatosis. Clinical course in 32 patients. N Engl J Med 1990; 323: 1254-60.
8. Fujimoto M, Ohara N, Sasaki H, Funakoshi T, Morita H, Deguchi $\mathrm{M}$, et al. Pregnancy complicated with pulmonary lymphangioleiomyomatosis: case report. Clin Exp Obstet Gynecol 2005; 32: 199200.

9. Morales JP, Georganas M, Khan MS, Dasgupta P, Reidy JF. Embolization of a bleeding renal angiomyolipoma in pregnancy: case report and review. Cardiovasc Intervent Radiol 2005; 28: 265-8.

10. Anker N, Francis D, Viskum K. 2 cases of lymphangioleiomyomatosis treated by hormonal manipulation. Ugeskr Laeger 1993; 155: 2354-6.

11. Klein M, Krieger O, Ruckser R, Rosen A, Waldner R, Preis P, et al. Treatment of lymphangioleiomyomatosis by ovariectomy, interferon alpha $2 \mathrm{~b}$ and tamoxifen--a case report. Arch Gynecol Obstet 1992; 252: 99-102.

12. Desurmont S, Bauters C, Copin MC, Dewailly D, Tonnel AB, Wallaert B. Treatment of pulmonary lymphangioleiomyomatosis using a GnRH agonist. Rev Mal Respir 1996; 13: 300-4.

13. Kpodonu J, Massad MG, Chaer RA, Caines A, Evans A, Snow NJ, et al. The US experience with lung transplantation for pulmonary lymphangioleiomyomatosis. J Heart Lung Transplant 2005; 24: 1247-53.

14. Woo MG, Sohn JT, Lee HK, Joung YK. Epidural anesthesia for cesarean section of pregnant woman with lymphangioleiomyomatosis. Korean J Anesthesiol 1996; 30: 740-5.

15. Suh MK, Seong KW, Jung SH, Kim SS. The effect of pneumoperitoneum and Trendelenburg position on respiratory mechanics during pelviscopic surgery. Korean J Anesthesiol 2010; 59: 329-34. 